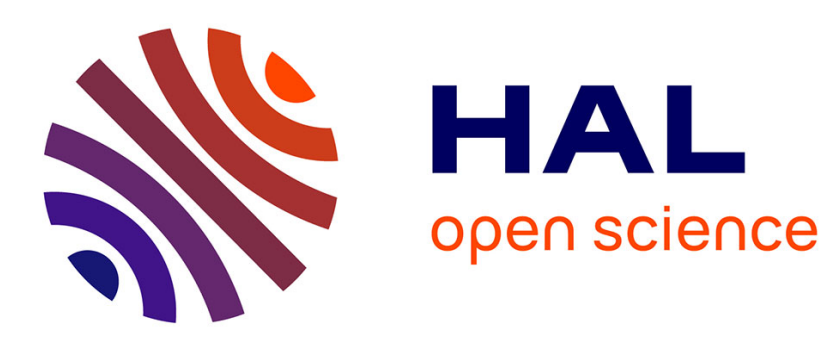

\title{
Solute Concentration Measurements in Diluted Solutions by means of Split Ring Resonators
}

Paris Velez, Javier Mata-Contreras, David Dubuc, Katia Grenier, Ferran Martín

\section{- To cite this version:}

Paris Velez, Javier Mata-Contreras, David Dubuc, Katia Grenier, Ferran Martín. Solute Concentration Measurements in Diluted Solutions by means of Split Ring Resonators. 48th European Microwave Conference, Sep 2018, Madrid, Spain. 4p., 10.23919/EuMC.2018.8541523 . hal-01951438

\section{HAL Id: hal-01951438 \\ https://hal.laas.fr/hal-01951438}

Submitted on 11 Dec 2018

HAL is a multi-disciplinary open access archive for the deposit and dissemination of scientific research documents, whether they are published or not. The documents may come from teaching and research institutions in France or abroad, or from public or private research centers.
L'archive ouverte pluridisciplinaire HAL, est destinée au dépôt et à la diffusion de documents scientifiques de niveau recherche, publiés ou non, émanant des établissements d'enseignement et de recherche français ou étrangers, des laboratoires publics ou privés. 


\title{
Solute Concentration Measurements in Diluted Solutions by means of Split Ring Resonators
}

\author{
Paris Vélez ${ }^{1}$, Javier Mata-Contreras ${ }^{1}$, David Dubuc ${ }^{2}$, Katia Grenier ${ }^{2}$, Ferran Martín ${ }^{1}$ \\ ${ }^{1}$ GEMMA/CIMITEC, Departament d'Enginyeria Electrònica, Universitat Autònoma de Barcelona, 08193 Bellaterra, Spain \\ ${ }^{2}$ MH2F, LAAS-CNRS, 7th, Avenue du Colonel Roche BP 5420031031 Toulouse, Cedex 4, France
}

E-mail: Ferran.Martin@uab.es

\begin{abstract}
This paper presents a sensing device, useful for the measurement of small concentrations of solute content in liquids, based on a splitter/combiner microstrip structure loaded with a pair of split ring resonators (SRRs) in a symmetric configuration. The operation principle is similar to differential sensing, where one of the SRRs is put in contact with the reference liquid (the solvent), whereas the solution (or liquid under test -LUT) is forced to flow on top of the other SRR, the sensing element. To this end, fluidic channels are added on top of the SRRs, which are covered by a dry film in order to avoid substrate absorption. The asymmetry, caused by the presence of solute content in the LUT, modifies the response of the structure with regard to the one with identical liquids (pure solvent) in both channels, and the solute concentration can be inferred. In this work, it is demonstrated that glucose and sodium concentrations as small as $1 \mathrm{~g} / \mathrm{L}$ and $0.5 \mathrm{~g} / \mathrm{L}$, respectively, in DI water can be measured.
\end{abstract}

Keywords - Split ring resonators (SRRs), microwave sensors, microstrip technology, solute concentration measurements.

\section{INTRODUCTION}

Metamaterial-inspired resonators, such as split ring resonators (SRRs), complementary split ring resonators (CSRRs) and other related resonators, have been used for sensing purposes in many different applications. Most of these sensors are based on planar configurations of transmission lines loaded with the previous resonant elements [1]-[26], and the general sensing principle relies on the effects that the variable under measurement (measurand) causes in the frequency response. Such effects are manifested as variations in the notch (or notches) associated to the presence of the resonant elements in close proximity to the line. Following this general principle, three main sensing strategies in transmission lines with metamaterial loading have been considered to date: (i) notch frequency and depth variation, (ii) coupling modulation, and (iii) frequency splitting.

In the first group of sensors, the measurand changes the (fundamental) resonance frequency of the resonant element and, consequently, the notch (or transmission zero) frequency in the frequency response experiences a variation. These sensors are of special interest in applications devoted to dielectric characterization of materials [1]-[8], since metamaterial-inspired resonators are, in general, very sensitive to the properties of the surrounding medium. Thus, changes in the permittivity of the material under test (MUT) affect the resonance frequency of the considered resonator (through variation in the capacitance), provided such MUT is in contact to the sensing resonator or in close proximity to it (dielectric loading). The dissipation factor of the MUT also influences the total losses of the resonator, thereby modifying the notch depth, as compared to the one resulting in the sensing structure without dielectric loading.

In coupling modulation sensors, a transmission line is symmetrically loaded with a symmetric resonator, and the considered resonator must exhibit a symmetry plane of different electromagnetic sort (electric or magnetic wall) at the fundamental resonance than the one of the line [14]-[15]. Under these circumstances, electromagnetic coupling between the line and the resonator is prevented, and the structure is allpass in the vicinity of the fundamental resonance. However, by truncating symmetry, e.g., by means of an asymmetric dielectric loading, or through a relative (linear or angular) displacement between the resonator and the line, line-toresonator coupling arises, and a notch in the frequency response (with depth intimately related to the level of asymmetry) is originated. These sensors have been mainly applied to the measurement of space variables such as displacement and velocity [13],[16]-[23].

Finally, in frequency splitting sensors a line is symmetrically loaded with a pair of resonant elements [9][12],[25]. If symmetry is preserved, a single notch at the resonance frequency arises. However, by truncating symmetry, two notches appear, and the difference between the notch frequencies and depths depends on the level of asymmetry. Hence, the incremental notch frequency and the incremental notch depth can be used as output variables for sensing. This sensing approach is similar to differential sensing, i.e., one resonator is loaded with a reference sample, whereas the other one is loaded with the sample under test (or MUT). Thus, differential properties between the reference sample and the sample under test can be inferred, and these sensors are robust against cross sensitivities, such as those related to environmental effects (temperature, moisture, etc.), as long as ambient factors are seen as common-mode stimulus by these sensors. Recently, a splitter/combiner configuration for this type of sensors was proposed [12] in order to alleviate the sensitivity degradation caused by inter-resonator coupling, and these sensors where applied in [25] to the measurement of the complex dielectric constant of liquids.

In this paper, a splitter/combiner microstrip structure loaded with SRRs is applied to the measurement of solute concentration in diluted solutions, particularly, glucose and 
sodium content in DI water. The main relevant aspect of the proposed sensor is its potential to resolve solute concentrations as small as $1 \mathrm{~g} / \mathrm{L}$ and $0.5 \mathrm{~g} / \mathrm{L}$ for glucose and sodium, respectively. Moreover, it will be shown that measuring several solute concentrations simultaneously is possible by simply cascading multiple splitter/combiners with SRRs tuned to different frequencies.

\section{THE PROPOSED SENSOR AND SENSING PRINCIPLE}

The proposed sensor consists of a splitter/combiner configuration implemented in microstrip technology, where each branch is loaded with a SRR, as depicted in the layout shown in Fig. 1(a) (where dimensions are indicated). The microwave structure has been fabricated on the Rogers RO3010 substrate with thickness $h=1.27 \mathrm{~mm}$, dielectric constant $\varepsilon_{r}=10.2$ and dissipation factor tand $\delta=0.0023$, by means of a $L P K F H 100$ milling machine. On top of the gap regions of the SRRs (the most sensitive regions to the effects of a dielectric load) we have placed fluidic channels for dielectric loading with liquids. The photograph of the complete sensor (including the microwave structure plus the fluidic channels and necessary mechanical parts) is depicted in Fig. 1 (b). The fluidic channels, with dimensions $h_{c h}, l_{c h}$, and $w_{c h}$, are made of polydimethylsiloxane (PDMS), and they are covered by polyether ether ketone $(P E E K)$, in order to provide mechanical stability and accommodate the fluidic connectors for liquid injection through a syringe (the details of the fluidic channels and mechanical parts can be seen in Fig. 2). It is important to highlight that, in order to avoid liquid absorption by the substrate, a dry film (with thickness $50 \mu \mathrm{m}$ and dielectric constant 3.56) has been grown between the fluidic channels and the microwave structure.

(a)

(b)

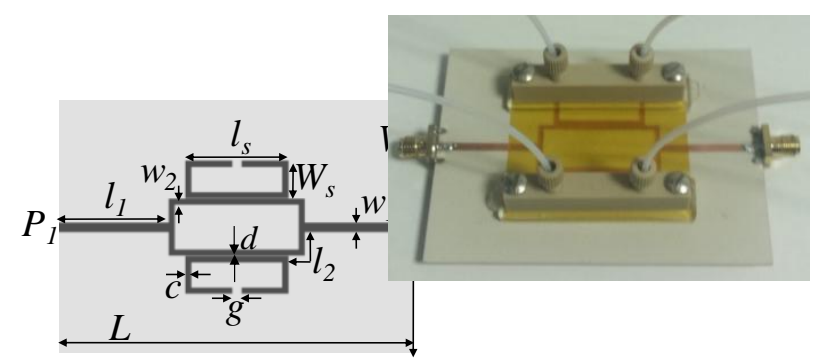

Fig. 1. Layout (a) and photograph (b) of the splitter/combiner structure loaded with SRRs. Dimensions are: $L=86 \mathrm{~mm}, W=62 \mathrm{~mm}, l_{1}=27 \mathrm{~mm}, w_{1}=2.22$ $\mathrm{mm}, l_{s}=25 \mathrm{~mm}, W_{s}=9 \mathrm{~mm}, c=1.4 \mathrm{~mm}, g=2.4 \mathrm{~mm}, d=0.2 \mathrm{~mm}, l_{2}=9.21$ $\mathrm{mm}$, and $w_{2}=1.34 \mathrm{~mm}$. The ground plane is depicted in grey.

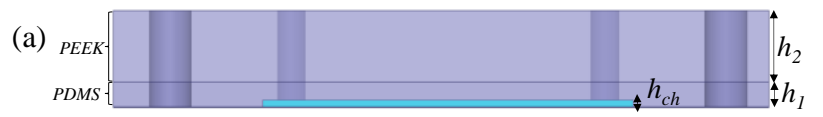

(b)

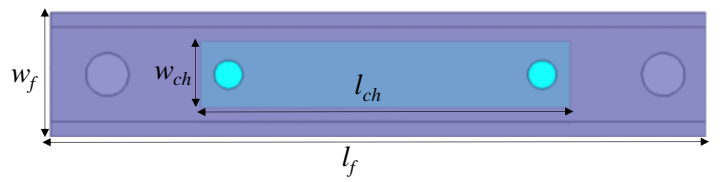

Fig. 2. Lateral (a) and top (b) views of mechanical and fluidic parts of the microwave sensor and relevant dimensions. $h_{c h}=1.5 \mathrm{~mm}, l_{c h}=26 \mathrm{~mm}$, $w_{c h}=4.6 \mathrm{~mm}, l_{f}=46 \mathrm{~mm}, w_{f}=12.6 \mathrm{~mm}, h_{l}=3 \mathrm{~mm}$, and $h_{2}=9 \mathrm{~mm}$.
The sensing principle is frequency splitting, similar to the one used in [25]. In that work, the sensor was devoted to the measurement of the complex dielectric constant of mixtures of ethanol in DI water, considering DI water as reference liquid and the solution of ethanol/DI water as liquid under test (LUT). In that work, the minimum volume fraction of ethanol in DI water that could be resolved was $5 \%$, similar to those found in other papers [7],[8]. The complex dielectric constant in the different solutions (with different volume fraction of ethanol) was obtained from the frequency and magnitude (depth) difference between the two notches generated by asymmetry. To this end, calibration curves were obtained from the knowledge of the complex dielectric constant of pure DI water and pure ethanol.

In this paper, the objective is the determination of solute concentration in considerably diluted solutions. Hence small asymmetries are expected by using as reference liquid the solvent and the solution as liquid under test. Therefore, to be able to detect such small concentrations of solute, it is necessary to slightly modify the sensing strategy. Thus, rather than obtaining the transmission coefficient (as in [25]), we will obtain the normalized transmission coefficient, that is, the transmission coefficient divided by the one that results when the LUT channel and reference channels are loaded with the solvent. The latter presents a single notch in the vicinity of the fundamental resonance of the SRRs, whereas the frequency response with solvent in the reference channel and a solution in the LUT channel exhibits in general two peaks. However, such peaks do not appear if the solute concentration does not produce enough asymmetry, but in the normalized transmission coefficient, two lobes (a positive and negative) are clearly visible, as will be demonstrated in the next section, and it is possible to detect very small concentrations, or volume fraction of solute.

\section{SENSOR VALIDATION}

To validate the functionality of the sensing device for the measurement of solute concentration in diluted solutions, we have first considered glucose as solute and DI water as solvent. Figure 3(a) shows the measured transmission coefficient for different concentrations of glucose in the LUT channel, as well as the response without glucose content. As anticipated, the responses are very similar due to the small asymmetries generated with the considered concentrations. However, in the normalized transmission coefficient [Fig 3(b)], the different responses can be clearly discriminated. The presence of the two lobes (one positive and the other one negative) is consequence of the frequency shift generated by the (slight) asymmetry. The system is able to detect glucose concentrations as small as $1 \mathrm{~g} / \mathrm{L}$, which is a very good resolution as compared to literature (see Table I).

TABLE I

COMPARISON OF VARIOUS MICROWAVE FLUIDIC SENSORS FOR GLUCOSE CONCENTRATION MEASUREMENT

\begin{tabular}{c|c|c|c} 
Ref. & $\begin{array}{c}\text { Max. sensitivity } \\
(\mathrm{dB} / \mathrm{g} / \mathrm{L})\end{array}$ & $\begin{array}{c}\text { Resolution } \\
(\mathrm{g} / \mathrm{L})\end{array}$ & $\begin{array}{c}\text { Dynamic } \\
\text { range }(\mathrm{g} / \mathrm{L})\end{array}$ \\
\hline$[27]$ & 0.003 & 1 & 300 \\
\hline$[28]$ & 1.75 & 1.5 & 5.5 \\
\hline
\end{tabular}




\begin{tabular}{c|c|c|c}
\hline$[29]$ & 0.017 & 10 & 150 \\
\hline$[30]$ & 0.003 & 5 & 300 \\
\hline This work & $\mathbf{0 . 0 5 5}$ & $\mathbf{1}$ & $\mathbf{1 0 0}$ \\
\hline
\end{tabular}

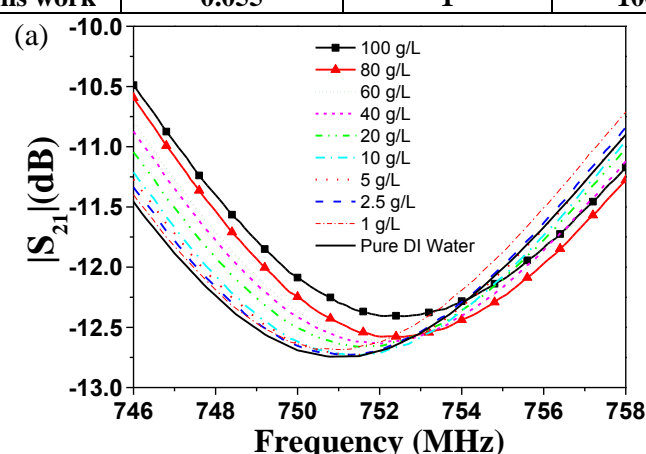

(b)

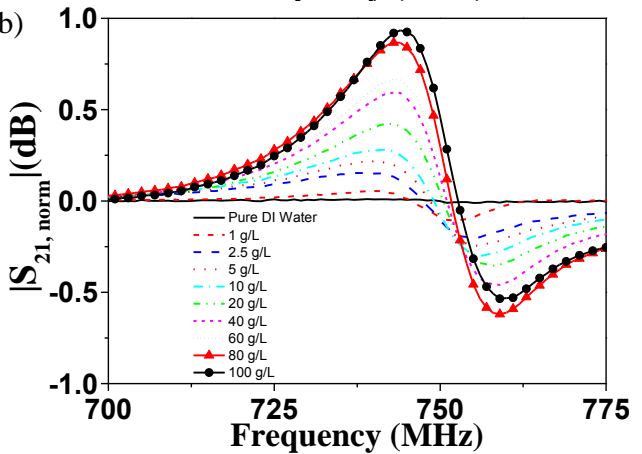

Fig. 3. Transmission coefficient (a) and normalized transmission coefficient (b) for different concentrations of glucose in DI water.

As the output variable of the sensor we have considered the maximum value of the normalized transmission coefficient expressed in $\mathrm{dB}$. Figure 4 depicts the variation of the output variable with glucose concentration (the input variable). From this data, we have obtained the following calibration curve,

$$
[G l u] g / L=110.53\left|S_{21, \text { norm }}\right|_{d B}^{2}-0.6314\left|S_{21, \text { norm }}\right|_{d B}
$$

which exhibits a correlation coefficient of $\mathrm{R}^{2}=0.9961$, and provides the glucose concentration from the measurement of the maximum value of the normalized transmission coefficient. The sensitivity, defined as the derivative of the maximum transmission coefficient with respect to glucose concentration, is a maximum in the limit when the glucose concentration tends to zero, and then it progressively decreases. The maximum value has been found to be $0.055 \mathrm{~dB} /(\mathrm{g} / \mathrm{L})$.

With the proposed system, it is possible to measure the solute concentration in several solutions simultaneously. To this end, a multi splitter/combiner structure is needed. As a proof-of-concept, we have fabricated the two-sensing device depicted in Fig. 5, where two splitter/combiners can be appreciated. The sensor on the left is identical to the one of Fig. 1 (b), whereas the one of the right has smaller dimensions, in order to locate the lobes in the normalized transmission coefficient at different frequencies and avoid overlapping. In this case, the structure has been used to measure the concentration of sodium in DI water.

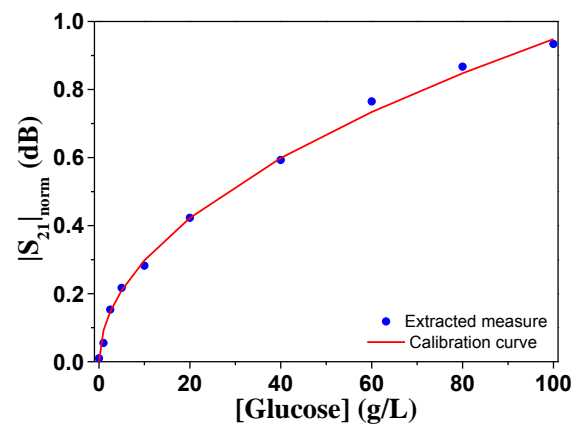

Fig. 4. Dependence of the glucose concentration with the maximum value of the normalized transmission coefficient (expressed in $\mathrm{dB}$ ). The calibration curve is also depicted.

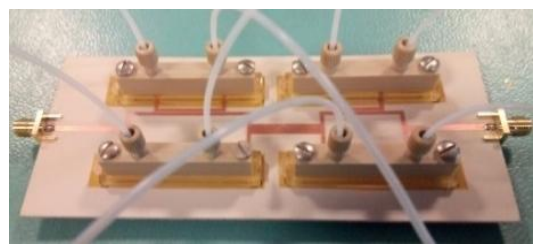

Fig. 5. Photograph of the fabricated two-sensing device. Dimensions of the second sensor, in reference to Fig. 1 , are: $l_{1}=23 \mathrm{~mm}, w_{1}=3.82 \mathrm{~mm}, l_{s}=15$ $\mathrm{mm}, W_{s}=9 \mathrm{~mm}, c=1.4 \mathrm{~mm}, g=2.4 \mathrm{~mm}, d=0.2 \mathrm{~mm}, l_{2}=11.1 \mathrm{~mm}$, and $w_{2}=$ $1.34 \mathrm{~mm}$.

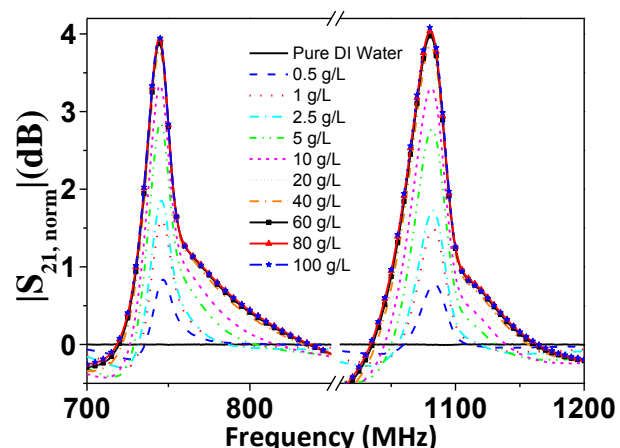

Fig. 6. Normalized transmission coefficient for the device of Fig. 6 for different concentrations of sodium in DI water (identical in both channels).

Figure 6 depicts the normalized transmission coefficient for different concentrations of sodium (identical in both sensors). It can be seen that the responses for different concentration levels are clearly distinguished in both sensors, and the peaks are clearly separated. Moreover, the maximum value of the normalized transmission coefficient is roughly the same for both sensors, provided the sodium concentration is also the same. Hence, a single calibration curve sufficies for the determination of sodium content. Nevertheless, note that the magnitude of the normalized transmission coefficient depends on the considered type of solute, and therefore, each solute needs its own calibration curve. Particularly, sodium in DI water behaves as an ion, hence altering significantly the conductivity, as compared to glucose. For this reason the variation of the normalized transmission coefficient is stronger when sodium is considered. The maximum sensitivity in this case has been found to be $1.609 \mathrm{~dB} /(\mathrm{g} / \mathrm{L})$.

\section{CONCLUSIONS}

In conclusion, a sensor for the determination of solute concentrations in diluted solutions has been presented. It is 
based on a splitter/combiner microstrip structure loaded with a pair of SRRs and fluidic channels on top of it (the reference channel for the reference liquid -solvent-, and the LUT channel for the liquid under test -solution). The sensing principle is based on the measurement of the normalized transmission coefficient (i.e., the one resulting by loading the LUT channel with the solution, referred to the one obtained with the LUT channel loaded with the solvent). The sensor has been applied to the measurement of glucose and sodium content in aqueous solutions. The proposed sensor exhibits a maximum sensitivity of $0.055 \mathrm{~dB} /(\mathrm{g} / \mathrm{L})$ for glucose and 1.609 $\mathrm{dB} /(\mathrm{g} / \mathrm{L})$ for sodium, and the resolution is as small as $1 \mathrm{~g} / \mathrm{L}$ and $0.5 \mathrm{~g} / \mathrm{L}$ respectively. These resolutions are competitive with regard to other microwave sensors recently reported and it is by far smaller than the typical concentration levels of such substances in blood samples. Therefore, the proposed structure can be potentially envisaged for fast detection of pathologies related to glucose or electrolytic imbalance in blood. Further study is necessary and is currently under way for that purpose.

\section{ACKNOWLEDGMENTS}

This work was supported by MINECO-Spain (project TEC2016-75650-R), Generalitat de Catalunya (projects 2014SGR-157 and TECSPR15-1-0050), Institució Catalana de Recerca i Estudis Avançats (who awarded Ferran Martín), and by FEDER funds.

\section{REFERENCES}

[1] M. Puentes, Planar Metamaterial Based Microwave Sensor Arrays for Biomedical Analysis and Treatment, Springer, Heidelberg, Germany, 2014.

[2] A. Ebrahimi, W. Withayachumnankul, S. Al-Sarawi, D. Abbott, "Highsensitivity metamaterial-inspired sensor for microfluidic dielectric characterization," IEEE Sensors J., vol. 14, no. 5, pp. 1345-1351, May 2014.

[3] M. Schueler, C. Mandel, M. Puentes, and R. Jakoby, "Metamaterial inspired microwave sensors," IEEE Microw. Mag., vol. 13, no. 2, pp. 57-68, Mar. 2012.

[4] M. S. Boybay and O. M. Ramahi, "Material characterization using complementary split-ring resonators," IEEE Trans. Instrum. Meas., vol. 61, no. 11, pp. 3039-3046, Nov. 2012.

[5] C.-S. Lee and C.-L. Yang, "Complementary split-ring resonators for measuring dielectric constants and loss tangents," IEEE Microw. Wireless Compon. Lett., vol. 24, no. 8, pp. 563-565, Aug. 2014.

[6] C.-L. Yang, C.-S. Lee, K.-W. Chen, and K.-Z. Chen, "Noncontact measurement of complex permittivity and thickness by using planar resonators," IEEE Trans. Microw. Theory Techn., vol. 64, no.1, pp. 247-257, Jan. 2016.

[7] W. Withayachumnankul, K. Jaruwongrungsee, A. Tuantranont, C. Fumeaux, and D. Abbott, "Metamaterial-based microfluidic sensor for dielectric characterization," Sens. Actuators A, Phys., vol. 189, pp. 233237, Jan. 2013.

[8] A. Salim and S. Lim, "Complementary split-ring resonator-loaded microfluidic ethanol chemical sensor," Sensors, vol. 16, no. 11, pp. 1$13,2016$.

[9] A. K. Horestani, J. Naqui, Z. Shaterian, D. Abbott, C. Fumeaux, and F. Martín, "Two-dimensional alignment and displacement sensor based on movable broadside-coupled split ring resonators," Sensors and Actuators A, vol. 210, pp. 18-24, April 2014.

[10] L. Su, J. Naqui, J. Mata-Contreras, and F. Martín "Modeling metamaterial transmission lines loaded with pairs of coupled split ring resonators," IEEE Ant. Wireless Propag. Lett., vol. 14, pp. 68-71, 2015.

[11] L. Su, J. Naqui, J. Mata-Contreras, and F. Martín, "Modeling and applications of metamaterial transmission lines loaded with pairs of coupled complementary split ring resonators (CSRRs)," IEEE Ant. Wireless Propag. Lett., vol. 15, pp. 154-157, 2016.

[12] L. Su, J. Mata-Contreras, J. Naqui, and F. Martín, "Splitter/combiner microstrip sections loaded with pairs of complementary split ring resonators (CSRRs): modeling and optimization for differential sensing applications," IEEE Trans. Microw. Theory Techn., vol. 64, pp. 43624370, Dec. 2016.

[13] J. Naqui, M. Durán-Sindreu and F. Martín, "Novel sensors based on the symmetry properties of split ring resonators (SRRs)," Sensors, vol 11, pp. 7545-7553, 2011.

[14] F. Martín, Artificial Transmission Lines for RF and Microwave Applications, John Wiley, Hoboken, NJ, 2015.

[15] J. Naqui, Symmetry Properties in Transmission Lines Loaded with Electrically Small Resonators: Circuit Modeling and Applications, Springer, Heidelberg, Germany, 2016.

[16] J. Naqui, M. Durán-Sindreu, and F. Martín, "Alignment and position sensors based on split ring resonators," Sensors, vol. 12, pp. 11790-11797, 2012.

[17] A.K. Horestani, C. Fumeaux, S.F. Al-Sarawi, and D. Abbott, "Displacement sensor based on diamond-shaped tapered split ring resonator," IEEE Sens. J., vol. 13, pp. 1153-1160, 2013.

[18] A.K. Horestani, D. Abbott, C. Fumeaux, "Rotation sensor based on horn-shaped split ring resonator," IEEE Sens. J., vol. 13, pp. 3014-3015, 2013.

[19] J. Naqui and F. Martín, "Transmission lines loaded with bisymmetric resonators and their application to angular displacement and velocity sensors," IEEE Trans. Microw. Theory Techn., vol. 61, no. 12, pp. 4700-4713, Dec. 2013.

[20] J. Naqui and F. Martín, "Angular displacement and velocity sensors based on electric-LC (ELC) loaded microstrip lines," IEEE Sensors J., vol. 14, no. 4, pp. 939-940, Apr. 2014.

[21] A.K. Horestani, J. Naqui, D. Abbott, C. Fumeaux, and F. Martín, "Twodimensional displacement and alignment sensor based on reflection coefficients of open microstrip lines loaded with split ring resonators," Elec. Lett., vol. 50, pp. 620-622, Apr. 2014.

[22] J. Naqui and F. Martín, "Microwave sensors based on symmetry properties of resonator-loaded transmission lines: a review," Journal of Sensors, vol. 2015, Article ID 741853, 10 pages, 2015.

[23] J. Naqui, J. Coromina, A. Karami-Horestani, C. Fumeaux, and F. Martín, "Angular displacement and velocity sensors based on coplanar waveguides (CPWs) loaded with S-shaped split ring resonator (S-SRR)," Sensors, vol. 15, pp. 9628-9650, 2015.

[24] L. Su, J. Mata-Contreras, P. Vélez, F. Martín, "Estimation of the Complex Permittivity of Liquids by means of Complementary Split Ring Resonator (CSRR) Loaded Transmission Lines", 2017 IEEE MTT-S International Microwave Workshop Series on Advanced Materials and Processes (IMWS-AMP 2017), Pavia, Italy, 20-22 Sep. 2017.

[25] P. Vélez, L. Su, K. Grenier, J. Mata-Contreras, D. Dubuc, and F. Martín, "Microwave microfluidic sensor based on a microstrip splitter/combiner configuration and split ring resonators (SRR) for dielectric characterization of liquids", IEEE Sensors J.,vol. 17, pp. 6589-6598, Aug. 2017.

[26] J. Mata-Contreras, C. Herrojo, and F. Martín, "Application of split ring resonator (SRR) loaded transmission lines to the design of angular displacement and velocity sensors for space applications", IEEE Trans. Microw. Theory Techn., vol. 65, pp. 4450-4460, Nov. 2017.

[27] A. Bababjanyan, H. Melikyan, S. Kim, J. Kim, K. Lee, and B. Friedman, "Real-time noninvasive measurement of glucose concentration using a microwave biosensor," J. Sensors, vol. 2010, 2010.

[28] S. Kim, H. Melikyan, J. Kim, A. Babajanyan, J.-H. Lee, L. Enkhtur, B. Friedman, and K. Lee, "Noninvasive in vitro measurement of pig-blood D-glucose by using a microwave cavity sensor," Diabetes Res. Clin. Pract., vol. 96, no. 3, pp. 379-384, 2012.

[29] N. Sharafadinzadeh, M. Abdolrazzaghi1, M. Daneshmand, "Highly sensitive microwave split ring resonator sensor using gap extension for glucose sensing", 2017 IEEE MTT-S International Microwave Workshop Series on Advanced Materials and Processes (IMWS-AMP 2017), Pavia, Italy, 20-22 Sep. 2017.

[30] J. Kim, A. Babajanyan, A. Hovsepyan, K. Lee and B. Friedman, "Microwave dielectric resonator biosensor for aqueous glucose solution", Rev. Sci. Instrum., vol. 79, paper 086107, 2008. 